\title{
The Hygienic Assessment of School Educational Programs
}

\author{
Elena A. Tkachuk ${ }^{1,2,3^{*}}, \mathrm{PhD}, \mathrm{ScD}$; Inna V. Mylnikova ${ }^{1}, \mathrm{PhD}, \mathrm{ScD}$; \\ Natalia V. Efimova ${ }^{1}, \mathrm{PhD}, \mathrm{ScD}$ \\ ${ }^{1}$ East-Siberian Institute of Medical and Ecological Research, Angarsk, the Russian Federation \\ ${ }^{2}$ Irkutsk State Medical University, Irkutsk, the Russian Federation \\ ${ }^{3}$ Scientific Centre for Family Health and Human Reproduction Problems, Irkutsk, the Russian Federation
}

\begin{abstract}
Background: The study presents a methodology for the hygienic assessment of school educational programs from the point of view of safety for the health of students and of effectiveness in improving the quality of education. The aim of the study was a hygienic assessment of educational programs in primary schools.

Methods and Results: The study involved primary school students $(\mathrm{n}=245)$ aged between 8 and 9.5 years: 120 children studying under the "Planet of knowledge" program (Group 1) and 125 children studying under the "Primary school of the XXI century" program (Group 2). The hygienic factors are studied using the methodology of assessing the intensity of educational work and the conditions of the organization of the educational process. The obtained data are compared with the main criteria of the state of children's neuropsychological development. We found that the program "Primary school of the XXI century" is characterized by the intensity of educational work ( $2.7 \pm 0.13$ points $)$ and approaches to the third degree, according to the criterion of intellectual loads. In contrast, the program "Planet of knowledge" is characterized by a lower intensity of educational work $-2.1 \pm 0.08$ points $(P=0.000)$. The indicators of sensory and emotional intensity of educational work under the program "Primary school of the XXI century" were also statistically higher.

Conclusions: The high intensity of educational work does not ensure high rates and levels of intellectual development and mental performance of children. The hygienic assessment of children's educational activities should include a comprehensive hygienic examination of the educational program and the means used in the process of its implementation. An educational program may be allowed to be used in educational organizations only after a hygienic examination of its application in the educational process.(International Journal of Biomedicine. 2021;11(4):546-550.)
\end{abstract}

Key Words: schoolchildren $\bullet$ educational activity $\bullet$ educational programs $\bullet$ hygiene $\bullet$ neuropsychological development

For citation: Tkachuk EA, Mylnikova IV, Efimova NV. The Hygienic Assessment of School Educational Programs. International Journal of Biomedicine. 2021;11(4):546-550. doi:10.21103/Article11(4)_OA24

\section{Introduction}

The education system has undergone serious changes over the past decades. The modernization allowed the use of innovative pedagogical technologies, which ideally should have provided an individual approach and improved the quality of education. Despite the measures taken and the increasing educational load, the state of children's health is deteriorating while the quality of education is not improving. ${ }^{(1,2)}$ Many

*Corresponding author: Prof. Elena A. Tkachuk, PhD, ScD. East-Siberian Institute of Medical and Ecological Research, Angarsk, the Russian Federation.E-mail: zdorowie38@gmail.com methods have been developed and studies are being conducted to assess the achievements of students and the reasons for the poor quality of education. (3) Therefore, understanding the causes of the deterioration in children's health and the poor quality of education is the primary task of building an education development strategy.

First of all, the search for solutions to educational problems should be sought in accordance with the age characteristics of children (physical, mental, social) and the hygienic conditions of the organization of the educational process, the core of which is pedagogical technology. This means that the hygienic assessment of pedagogical technology is a key link in an organization's choice of such technology. 
Modern researchers have shown that a high level of intensification of education (provided for by the training technology) leads to a decrease in educational results due to a decrease in students' health, such as disorders of the nervous system, manifestations of deviant behavior, mental disorders, hyperactivity and a decrease in motivation for academic work. In combination with an increase in the level of informatization, the devaluation of fundamental disciplines (since informatization prefers the "final result") leads to a decrease in the level of a student's cognitive activity. ${ }^{(1,4-6)}$

Educational organizations are increasingly using modern, innovative pedagogical technologies and programs aimed at improving the quality of education and meeting the needs of society for the education and socialization of children.

In this regard, the study of the hygienic characteristics of pedagogical technology and educational programs becomes particularly relevant, justifying the use of the study results by educational organizations.

The search for scientific approaches to studying the hygienic characteristics of educational programs allowed us to formulate the purpose of this study. The aim of the study was a hygienic assessment of educational programs in primary schools.

\section{Materials and Methods}

Our study was conducted in the primary classes of the children's education center No.47 and of the secondary school No.67 in Irkutsk. Hygienic conditions in educational institutions met the requirements of sanitary rules and did not differ significantly statistically.

The study involved primary school students $(n=245)$ aged between 8 and 9.5 years: 120 children studying under the "Planet of knowledge" program (Group 1) and 125 children studying under the "Primary school of the XXI century" program (Group 2).

The peculiarity of the training system under "Planet of knowledge" is the creation of an integral educational space, the unity of conceptual approaches, and the achievement of high learning results due to the effective combination of regular and extracurricular activities.

The peculiarity of the training system under "Primary school of the XXI century" is the orientation to the individual capabilities and characteristics of the child; the priority of problem-research activities, taking into account the pace of student advancement; the correction of emerging difficulties, the formation of creative thinking and imagination, and high erudition and cultural background.

Groups were formed by a continuous method. The children in the studied groups had no acute and decompensated chronic diseases or congenital pathology; sexual development corresponded to age; the level of physical activity was average - physical culture classes within the school curriculum.

Statistically significant differences in the physical development of the children were not identified
This study is based on the methodology we developed earlier for assessing the intensity of the educational work of schoolchildren. ${ }^{(7)}$ The methodology is based on an assessment of the student's working conditions, as a set of factors of the educational process, and the educational environment in which the student's activities are carried out. The assessment of the intensity of the schoolchildren's work characterizes the educational process, reflects the load mainly on the central nervous system, the sensory organs, and the emotional sphere of the child. ${ }^{(7)}$

The monotony of loads was assessed by timing observations of schoolchildren during a typical school week. The assessment was carried out throughout the school year. The mode of educational activity was evaluated according to the actual duration of the study time (taking into account the educational process at school, the system of additional education and the preparation of homework). The sensory and emotional loads were assessed in accordance with different levels of complexity of educational activities..$^{(7)}$

Tension was assessed in points and was based on the average score of all the criteria for the intensity of educational work: Thus, the light degree of educational work corresponded to 1 point, the average degree -2 points and the heavy degree $-3-4$ points. $^{(7)}$

The assessment was carried out by observing groups of children over time, as well as individual surveys of children, parents, and teachers. At the same time, all types of educational activities were taken into account, including homework and work in circles and sections of additional education.

The obtained indicators were correlated with indicators of intellectual development (according to the Raven test), ${ }^{(8)}$ mental performance (according to V.Ya. Anfimov) ${ }^{(9)}$ and memory. ${ }^{(10)}$

The indicators of intellectual development were evaluated by means of the Raven test. At first, the assessment was carried out in points, then the percentage of completed tasks was estimated. At the same time, 5 degrees of intellectual development were distinguished: Degree 1 (high intelligence) - more than $95 \%$ of test tasks were completed; Degree 2 (above average intelligence) - 75\%-94\%; Degree 3 (average intelligence) - 25\%-74\%; Degree 4 (below-average intelligence) - 5\%-24\%; Degree 5 (defect) - below 5\%. ${ }^{(11)}$ The results of the series in the Raven test were evaluated separately in order to identify differentiated indicators of intellectual development: The ability to determine the principle of interrelation in the structure of matrices (A series), the principle of analogy between pairs of figures (series B), the principle of progressive changes in the figures of matrices $(\mathrm{C}$ series), the principle of rearrangement of figures (D series), and the principle of decomposition of figures into elements (E series) were distinguished.

The evaluation was carried out by the number of errors made and the number of rows viewed. Each missing line was equated to one error. The productivity coefficient $\mathrm{Q}$ was calculated using the formula:

$Q=c^{2} / c+d$,

where $c$ is the number of rows viewed; $d$ is the number of errors (errors were not standardized). ${ }^{(9)}$ 
The efficiency was evaluated according to V.Ya. Anfimov's curly tables. ${ }^{(9)}$

The study was conducted in accordance with ethical principles of the WMA Declaration of Helsinki (1964, ed. 2013). Written informed consent was obtained from the participant's parent/guardian.

Statistical analysis was performed using the Statistica 10 software package (Stat-Soft Inc., USA). Analysis of the distribution of values obtained was performed using the Kolmogorov-Smirnov test. The mean (M) and standard error of the mean (SEM) were deduced. For data with normal distribution, inter-group comparisons were performed using Student's t-test. Differences of continuous variables departing from the normal distribution were tested by the Mann-Whitney U-test. The frequencies of categorical variables were compared using Pearson's chi-squared test. A probability value of $P<0.05$ was considered statistically significant.

\section{Results}

The study showed that the intensity of educational work was higher in children studying under the program "Primary school of the XXI century" (Table 1). The intellectual loads under this program amounted to $2.7 \pm 0.13$ points (Group 2 ), which was close to the third class of intensity of educational work due to the use of an approach aimed at improving student erudition by mastering a wide range of concepts, developing projects, and solving non-standard tasks. In Group 1, the intellectual loads were determined by the performance of simple tasks that were distributed both for the regular and extracurricular activities and amounted to the second class of the intensity of educational work ( $2.1 \pm 0.08$ points).

Table 1.

The intensity of educational work, points

\begin{tabular}{|l|c|c|c|}
\hline \multicolumn{1}{|c|}{ Variable } & $\begin{array}{c}\text { "Planet of } \\
\text { knowledge" } \\
(\mathrm{n}=120)\end{array}$ & $\begin{array}{c}\text { "Primary school } \\
\text { of the XXI } \\
\text { century" } \\
(\mathrm{n}=125)\end{array}$ & $P$-value \\
\hline Intellectual loads & $2.1 \pm 0.08$ & $2.7 \pm 0.13$ & 0.000 \\
\hline Sensory loads & $1.8 \pm 0.04$ & $1.6 \pm 0.05$ & 0.002 \\
\hline Emotional loads & $1.2 \pm 0.01$ & $1.4 \pm 0.07$ & 0.005 \\
\hline Monotony of loads & $1.6 \pm 0.05$ & $1.8 \pm 0.06$ & 0.011 \\
\hline Operating mode & $1.5 \pm 0.04$ & $1.8 \pm 0.05$ & 0.000 \\
\hline
\end{tabular}

The sensory loads in both groups were determined by the duration of the concentration time, the teaching tools used during the lesson as well as the time spent watching the video terminal monitors. In Group 1, the sensory loads were 1.6 \pm 0.05 points and were close to the second class of the intensity of educational work, and in Group $2-1.8 \pm 0.04$ points $(P=0.002)$.
The emotional loads during the work on the program «Primary school of the XXI century» were higher due to the importance of the assessment for the student and individual responsibility for the result, and amounted to $1.2 \pm 0.01$ points in Group 1, and 1.4 \pm 0.07 points in Group 2. In both groups of the study, the indicator of emotional loads corresponded to the first class of intensity of educational work but when compared, it was statistically different $(P=0.005)$.

The obtained data on the intensity of educational work allowed us to correlate the indicators of the intensity of educational work and the results of the neuropsychic development of children studying under various programs (Table 2).

Table 2 .

Conditions and learning outcomes (the intellectual loads)

\begin{tabular}{|l|c|c|}
\hline The training program & $\begin{array}{c}\text { The level of tension } \\
\text { (the intellectual } \\
\text { loads), points }\end{array}$ & $\begin{array}{c}\text { The level of } \\
\text { intelligence, points }\end{array}$ \\
\hline "Planet of knowledge" & $2.1 \pm 0.08$ & $24.9 \pm 0.7$ \\
\hline $\begin{array}{l}\text { "Primary school of the } \\
\text { XXI century" }\end{array}$ & $2.7 \pm 0.13$ & $23.1 \pm 0.7$ \\
\hline$P$-value & 0.000 & 0.07 \\
\hline
\end{tabular}

The indicators of the Raven test (the percentage of completed tasks) did not increase during training with an increased intellectual load, as one would expect (Table 3).

Table 3.

The indicators of the Raven test, points

\begin{tabular}{|c|c|c|c|}
\hline $\begin{array}{c}\text { Raven's } \\
\text { progressive } \\
\text { table series }\end{array}$ & $\begin{array}{c}\text { "Planet of } \\
\text { knowledge" }\end{array}$ & $\begin{array}{c}\text { "Primary school } \\
\text { of the XXI } \\
\text { century" }\end{array}$ & $P$-value \\
\hline A series & $9.9 \pm 0.4$ & $9.8 \pm 0.4$ & 0.860 \\
\hline B series & $7.1 \pm 0.5$ & $5.9 \pm 0.4$ & 0.062 \\
\hline C series & $2.5 \pm 0.3$ & $2.4 \pm 0.2$ & 0.782 \\
\hline D series & $4.3 \pm 0.3$ & $4.1 \pm 0.3$ & 0.638 \\
\hline E series & $1.1 \pm 0.2$ & $0.9 \pm 0.2$ & 0.480 \\
\hline Total & $24.9 \pm 0.6$ & $23.1 \pm 0.6$ & 0.035 \\
\hline
\end{tabular}

The study showed an inverse relationship between the number of completed tasks and the intensity of intellectual loads. The qualitative analysis of the Raven test results showed that the application of the principle of correlation in the structure of the matrices, the analysis of the structure of the base image and the detection of these features in one of a few 
fragments, and the merger of the fragment and its comparison with the surroundings of the main part of the test pattern are equally well formed by this training program.

The principle of identifying the analogies used in the series B scored slightly better in children of Group 1 and was $7.1 \pm 0.5$ points compared to $5.9 \pm 0.4$ points in Group 2 .

The $\mathrm{C}$ series of the Raven test involves identifying the principle of complication of figures; once students have identified this principle, they can pick out the missing figure. There were no statistically significant differences in this indicator.

The $\mathrm{D}$ series determines the ability to speculatively rearrange the figures in the matrix, both in horizontal and vertical positions. There were also no statistically significant differences in this series.

In the $\mathrm{E}$ series, the missing figures can be found by understanding the principle of analysis and synthesis of figures. This series was the most difficult to complete. Children of Group 2 had slightly lower results: $0.9 \pm 0.2$ points against $1.1 \pm 0.2$ points in Group 1 .

The absolute indicators (Table 3) of intelligence in the Raven test, while studying according to a standard training program, was statistically significantly higher and had a value of $24.9 \pm 0.6$ points, compared to $23.1 \pm 0.6$ points $(P=0.035)$ while studying according to enriched training programs.

The study of the mental performance of younger schoolchildren showed that studying under the program «Primary school of the XXI century» leads to an increase in the number of mistakes (17.5 \pm 0.6 in Group 2 versus $13.1 \pm 0.4$ in Group $1, P=0.000$ ), which may indicate chronic fatigue (Table 4). The productivity of mental labor under this training program is lower than when studying under the program "Planet of knowledge."

Table 4.

The indicators of mental performance

\begin{tabular}{|l|c|c|c|}
\hline \multicolumn{1}{|c|}{ The indicators } & $\begin{array}{c}\text { "Planet of } \\
\text { knowledge" }\end{array}$ & $\begin{array}{c}\text { "Primary school } \\
\text { of the XXI } \\
\text { century" }\end{array}$ & $P$-value \\
\hline $\begin{array}{l}\text { The number of rows } \\
\text { viewed (c) }\end{array}$ & $14.3 \pm 0.3$ & $14.5 \pm 0.3$ & 0.638 \\
\hline $\begin{array}{l}\text { The number of errors } \\
\text { made (d) }\end{array}$ & $13.1 \pm 0.4$ & $17.5 \pm 0.6$ & 0.000 \\
\hline $\begin{array}{l}\text { The productivity of } \\
\text { intellectual work (q) }\end{array}$ & $7.5 \pm 0.5$ & $6.6 \pm 0.4$ & 0.161 \\
\hline
\end{tabular}

\section{Discussion}

The study of the hygienic characteristics of school education shows that indicators of the intensity of educational activity can have a significant impact on the state of the nervous system (intellectual development, memory, mental performance). Significant changes in the indicators of the nervous system's functioning are observed when the indicator of the intensity of educational work approaches the third-degree severity. The constant impact of educational stress on the child's body subsequently leads inevitably to health disorders. ${ }^{(1)}$

Considering the high intensity of educational work, it is necessary to conduct a hygienic assessment of school education programs, which in conditions of school stress can have a serious negative impact on the health of children, without increasing the training and quality of acquired knowledge. Our research has shown that high intensity educational work, which means a higher level of stress, does not necessarily lead to higher academic achievements but leads to "chronic educational stress."

The intensity of educational work is largely determined by pedagogical technologies and programs, which include both the conditions of the educational process and the means of teaching.

Due to the hygienic examination of the educational program, it is possible to predict its impact on the health of children and on the educational effect.

As hygienic criteria for studying the educational program, it is proposed to use the intensity of educational work.

As sensitive criteria, we propose to use the pace of physical development, intellectual development, and mental performance.

\section{Conclusions}

1. The high intensity of educational work does not ensure high rates and levels of intellectual development and mental performance of children.

2. The hygienic assessment of children's educational activities should include a comprehensive hygienic examination of the educational program and the means used in the process of its implementation.

3. An educational program may be allowed to be used in educational organizations only after a hygienic examination of its application in the educational process.

\section{Acknowledgments}

This article contains material that has been discussed at the VIII International Research and Practical Conference «FUNDAMENTAL AND APPLIED ASPECTS OF REPRODUCTION» (December 2021, Irkutsk, Russia). The author thanks all researchers who participated in the oral discussion.

\section{Competing Interests}

The authors declare that they have no competing interests.

\section{References}

1. Kuchma VR, Stepanova MI. [The stress of schoolchildren: 
causes, consequences, prevention]. Russian Journal of Occupational Health and industrial Ecology. 2001;(8):32-37, 2001. [Article in Russian].

2. Osipova SI, Baranova IA, Ignatova VA. [Informatization of education as the object of pedagogical analysis]. Fundamental'nye Issledovaniia. 2011;12(3):506-510. [Article in Russian].

3. Kolmagorova AV. [The screening assessment of mental health at an early age]. Psikhoterapiia. 2007;(2):13-14. [Article in Russian].

4. Kuchma VR, Zvezdina IV, Zhigareva NS. [Medicalsocial aspects of health forming in children in junior school]. Voprosy Sovremennoi Pediatrii. 2008;7(4):9-12. [Article in Russian].

5. Tkachuk EA. [Indicators of mental health of pre-school children in Irkutsk amid the wide introduction of information technologies]. Kazan Medical Journal. 2013;94(6):864-866. [Article in Russian].

6. Tkachuk EA, Mylnikova IV, Efimova NV. [Hygienic assessment of schoolchildren's learning labour intensity].
Ekologiya cheloveka (Human Ecology). 2014;(6):20-24, 2014. [Article in Russian].

7. Tkachuk EA. The problems of evaluation of educational texts (monograph). Irkutsk: IrSTU Publishing house; 2009. [In Russian].

8. Kuchma VR. The hygiene of children and adolescents: Textbook. Moscow: GEOTAR-Media; 2008. [In Russian].

9. Gafurova NV. [Informatization of education as a pedagogical problem]. Modern problems of science and education. 2012;(3). Available from: https://scienceeducation.ru/ru/article/view?id=6199. [Article in Russian]. 10. Babansky YuK. The selected pedagogical works. Moscow: Pedagogika; 1989. [In Russian].

11. Hoare J, Fouche JP, Spottiswoode B, Donald K, Philipps $\mathrm{N}$, Bezuidenhout $\mathrm{H}$, Mulligan $\mathrm{C}$, Webster $\mathrm{V}$, Oduro $\mathrm{C}$, Schrieff L, Paul R, Zar H, Thomas K, Stein D. A diffusion tensor imaging and neurocognitive study of HIV-positive children who are HAART-naïve «slow progressors.» J Neurovirol. 2012 Jun;18(3):205-12. doi: 10.1007/s13365012-0099-9. 